\title{
Love, eye contact and the developmental origins of empathy $v$. psychopathy ${ }^{\dagger}$
}

Mark R. Dadds, Jennifer L. Allen, Bonamy R. Oliver, Nathan Faulkner, Katherine Legge, Caroline Moul, Matthew Woolgar and Stephen Scott

\section{Background}

A propensity to attend to other people's emotions is a necessary condition for human empathy.

\section{Aims}

To test our hypothesis that psychopathic disorder begins as a failure to attend to the eyes of attachment figures, using a 'love' scenario in young children.

\section{Method}

Children with oppositional defiant disorder, assessed for callous-unemotional traits, and a control group were observed in a love interaction with mothers. Eye contact and affection were measured for each dyad.

\section{Results}

There was no group difference in affection and eye contact expressed by the mothers. Compared with controls, children with oppositional defiant disorder expressed lower levels of affection back towards their mothers; those with high levels of callous-unemotional traits showed significantly lower levels of affection than the children lacking these traits. As predicted, the former group showed low levels of eye contact toward their mothers. Low eye contact was not correlated with maternal coercive parenting or feelings toward the child, but was correlated with psychopathic fearlessness in their fathers.

\section{Conclusions}

Impairments in eye contact are characteristic of children with callous-unemotional traits, and these impairments are independent of maternal behaviour.

\section{Declaration of interest}

None.
Parent-child interactions vary in the extent to which they support or protect against the development of antisocial behaviour in children. The development of an empirical base for understanding these interactions has largely relied on operant theory and direct observations as originally introduced by Patterson, Reid, Forehand and other pioneers. ${ }^{1}$ This science has led to a rich understanding of coercive cycles, and the contexts in which they occur, that facilitate aggression and antisocial behaviour, in terms both of developmental psychopathology and of prevention and treatment. ${ }^{2} \mathrm{~A}$ hallmark of the development of the aforementioned models has been the use of observational strategies that allow for the study of these cycles in clinics and laboratories. The predominant strategies have thus far been interactional tasks that provoke parent-child conflict and its resolution. Common examples include 'free play', compliance, problem-solving and teaching tasks in which parents and children are scored for various indices of cooperation, aggression, coercion and so forth. These tasks are excellent for delineating parenting styles that differentiate between children with aggressive and antisocial behaviour and healthy children, ${ }^{1,3}$ and have led to treatment technologies that produce reliable and clinically significant benefits for children with such behaviour problems. ${ }^{2}$ However, these observational technologies have not been particularly useful for differentiating between different groups of children with aggressive and antisocial behaviour. This is a major block to progress. The past two decades have seen increasing evidence emerge that the pathways into, through and out of such behaviour are heterogeneous, and that these differences are non-trivial in terms of aetiology, prognosis and treatment success. In this paper we focus on the division of children with aggressive and antisocial behaviour into 'hot' and 'cold' groups. ${ }^{4}$ The majority of these children - the 'hot' group - are impulsive, emotional, given to overly hostile interpretations of the world, have normal levels of empathy and are largely

†See editorial, pp. 175-176, this issue. reactive in their aggression. A smaller group - the 'cold' or 'high callous-unemotional' group - are underemotional, show problems with affective empathy, and demonstrate proactive or predatory as well as reactive aggression. Several reviews attesting to the robustness of the distinction between these groups have been published recently.,

It is of interest here that the distinction between low and high levels of callous-unemotional traits has important implications for parenting both as a causal and a treatment variable. Correlational studies, ${ }^{7,8}$ controlled treatment trials, ${ }^{9,10}$ and large behavioural genetic studies, ${ }^{11,12}$ have produced converging evidence that both callous-unemotional traits and aggressive and antisocial behaviour in the presence of such traits are relatively stable and insensitive to parental influences. ${ }^{13}$ That is, traditional models of coercion are less applicable to understanding the pathways these children take into and out of aggressive and antisocial behaviour. This is not surprising as the predominant models of callous-unemotional traits emphasise neuropsychiatric deficits in emotion processing. At present no methods exist for studying the early origins of these deficits in terms of how they are influenced by, and themselves influence, parenting styles.

The aim of this paper is to introduce a theory and novel methodology expressly designed for elucidating parent-child interactions that are sensitive to specific emotion-processing deficits in young children exhibiting aggressive and antisocial behaviour with and without callous-unemotional traits. We present data showing that measuring eye contact during a simple 'love' task may provide a marker of the emergence of callousunemotional traits early in the development of aggressive and antisocial behaviour.

One of the best-replicated deficits that characterise callousunemotional traits is an impairment in the ability to recognise fear stimuli. ${ }^{14}$ Although this is usually shown in an inability to recognise fearful faces, it holds too for impairments in recognising fear postures, sounds and startle stimuli. ${ }^{15-17}$ This deficit closely 
parallels similar problems shown by patients with amygdala damage, ${ }^{18}$ and is largely associated with a failure to direct attention to stimuli that normally elicit fear and distress. Indeed, when children with callous-unemotional traits are asked to attend to the eyes of fearful faces they show normal levels of fear recognition. ${ }^{19,20}$ Similarly, when adults with psychopathic disorder have their attention directed to fear-relevant information, they show normalised fear-potentiated startle responses. ${ }^{17}$ These findings have led theorists to suggest that a failure to attend to emotional stimuli may be a core characteristic of 'cold' varieties of aggressive and antisocial behaviour. Specifically, we have argued that a failure to attend to the eyes of attachment figures may be a critical feature of callous-unemotional traits that emerges very early and leads to cascading errors in the development of empathy and conscience. ${ }^{19-21}$ Consistent with this, early damage to the amygdala leads to cascading errors through the neural systems responsible for the development of higher-order systems underlying empathy and theory of mind. ${ }^{22}$

Attention to emotional stimuli such as fearful faces has typically been studied using computerised stimuli. An exception to this is a study in which boys with aggressive and antisocial behaviour with and without high levels of callous-unemotional traits were observed interacting with their parents in free play and 'emotion talk' situations. ${ }^{21}$ As predicted, high callousunemotional traits were associated with impairments in eye gaze towards parents; similar impairments were seen in the fathers but not the mothers of these boys with high levels of callousunemotional traits. These eye-gaze impairments were correlated with the boys' empathy levels and their ability to recognise fear faces. The interactions coded in this study were time-consuming because large amounts of data had to be sampled to derive rates of eye gaze, and the study did not include a control sample for which levels of eye contact could be compared. What we believe is needed is a parent-child interactional task that concentrates the interaction into a short but emotionally intense encounter for which reciprocated eye gaze is fundamental. Because such a task is conspicuous by its absence in the developmental psychology literature, we decided the best candidate would be a 'love' task in which the parent is asked to move close to the child, look the child in the eyes and say 'I love you'. We considered that this task would be comfortable for parents and, consistent with the study by Dadds et al, ${ }^{21}$ would show no difference in maternal eye contact on the basis of the child's level of callous-unemotional traits. In contrast to the earlier study, however, we predicted that the children's reciprocated eye gaze would differentiate those with low $v$. high levels of callous-unemotional traits.

\section{Method}

Participants were 24 children aged 4-8 years, two-thirds of whom were boys. Twelve children were diagnosed with oppositional defiant disorder and 12 children were recruited to serve as a healthy comparison group. The clinic group were self-referred by parents to the project at the Institute of Psychiatry, King's College London, after notices describing the study - and offering subsidised intervention for parents of oppositional and aggressive children - were distributed in south London. The main inclusion criterion was a primary diagnosis of conduct problems: oppositional defiant or conduct disorder according to DSM-IV criteria, assessed using the Diagnostic Interview Schedule for Children, Adolescents and Parents administered to parents by a clinical psychologist. ${ }^{23,24}$

Children were excluded if any full clinical diagnosis other than oppositional defiant or conduct disorder was present; however, subclinical comorbidity was permitted. Other criteria included age 4-8 years; no concurrent psychiatric treatment or medication; no global developmental delay; English as a first language; no significant speech problems or learning difficulties; and no major psychiatric illness or addiction in the mother. The control group was recruited through newspaper advertisements and flyers distributed at schools in the same south London region. The flyers asked for happy, confident children who had never seen a mental health professional (and their parents) to participate. All children in this group were screened to ensure the absence of any mental health problems.

There was no significant difference between the clinical and control groups on any of the demographic variables (Table 1). All mothers were the child's biological parent. Five mothers were the child's sole caregiver, one child belonged to a step/blended family and the remaining six children were members of their original two-parent family. Biological fathers of half of the clinic sample and three-quarters of the control sample agreed to participate; they did not attend the diagnostic or observational parts of the study, but completed a subsection of the personality inventory described below. Ethnic identity and household income were noted.

\section{Parental report measures}

Maternal reports on the Strengths and Difficulties Questionnaire (SDQ) were used to assess antisocial behaviour and to characterise the general level of adjustment in the children; callousunemotional traits were measured using the Antisocial Process Screening Device (APSD) ${ }^{25,26}$ Cronbach alpha values were 0.75 for APSD callous-unemotional traits and 0.69-0.79 for all subscales of the SDQ. Mothers' negative feelings towards their child were measured using a brief version of the Parent Feelings Questionnaire, ${ }^{27}$ containing three items from the negative and three from the positive feelings subscales $(\alpha=0.785)$. Mothers' reported Asperger symptoms in their child were measured using the Childhood Asperger Syndrome Test (CAST), a validated screening measure that is particularly useful for this age group (total score $\alpha=0.89$ ). ${ }^{28}$ Mothers' use of corporal punishment was measured using the relevant subscale of the Alabama Parent Questionnaire, ${ }^{29}$ and fearlessness was measured in fathers using the appropriate subscale of the well-established Psychopathic Personality Inventory (PPI). ${ }^{30}$

\section{Mother-child procedure: the 'I love you' task}

Mothers and children interacted in a playroom equipped with toys, a table and chairs, and videotaping equipment. The experimenter was unaware of the child's callous-unemotional status and was stationed in an adjacent room that provided both videotape and two-way mirror visual and audio access to the playroom. After approximately $30 \mathrm{~min}$ of free play and shared conversation, the mother was asked to show her child that she loves him or her. Verbal instructions for this task were given to mothers in advance over the telephone to ensure that the child was not aware of the task details. Instructions given over the telephone to the mother were as follows:

Experimenter: "I'm going to come back into the room to do one more game. Once I have gone, I'd like you to look [child's name] in the eyes and show him/her, in the way that feels most natural for you, that you love him/her." Following this phone call the mother and child continue with their activity. The experimenter then returns to the testing room and gives final instructions to the mother and child as follows Experimenter (before leaving testing room): "Great, that's almost it, thanks so much! One last thing before we finish, I'm just going to leave the room one more time to get something. I'll only be a couple of minutes, but while I am gone I'd like you to congratulate each other on how well you've both done today."

Recordings of the task were coded for mother and child levels of comfort and genuineness during the interaction, verbal and 
physical expressions of affection, and eye contact, both initiated and rejected, on five-point scales from 1 (not at all) to 5 (very much). Coders were graduate psychology research staff who had participated in the development of the task and coding procedures, and who were unaware of the children's callousunemotional trait scores. Coding began from the moment the experimenter left the testing room and continued until the experimenter re-entered the room $90 \mathrm{~s}$ later. Initiation and rejection scores for eye contact, verbal and physical affection scores were highly and negatively correlated, and so were combined by reversing 'rejection' scores and adding them to 'initiation' scores to form overall indices of affection and eye contact for parent and child. All recordings were coded by two coders masked to each other's ratings. Interrater reliabilities between the coders ranged from good to perfect agreement; intraclass correlations ranged from 0.645 to 1.00 . Procedural and coding manuals are available from the authors on request.

\section{Statistical analysis}

Analysis of variance (ANOVA) within PASW version 18 for Windows was used to test differences between the groups on each of the affection and eye-gaze measures. Because of the small sample size, where assumptions of normal distribution may be violated, and to check that relationships were statistically robust and not confounded by other variables, non-linear regression using bootstrapping to derive an empirical sample of the distribution was run in PASW version 18.

\section{Results}

The mean age of the participating children was 5.9 years (s.d. =0.6). In the clinical group, mothers' ages ranged from 24 to 46 years (mean 37.5 , s.d. $=6.9$ ). Mothers identified their ethnicity as White British or Irish $(n=9)$ or Black/mixed $(n=3)$. Child ethnicity was identified as White British $(n=9)$ or Black/mixed $(n=3)$. The fathers were identified as White British or Irish $(n=10)$ or Black/mixed $(n=2)$. Household income ranged from $£ 101-175$ to more than $£ 1000$ per week; the median

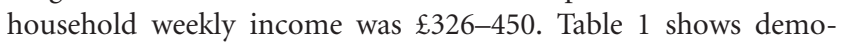
graphic and adjustment data for the clinic $v$. control groups. There was no significant differences for any demographic variables; however, as expected, the clinic sample had poorer adjustment than controls on all scales of the SDQ and callous-unemotional traits from the APSD. We checked whether callous-unemotional trait scores within the clinic group were significantly correlated with other variables that might confound the relationship of these traits to the main dependent measures. Callous-unemotional traits were significantly correlated with family income $(r=0.692$, $P<0.05)$ such that children with high trait scores had higher

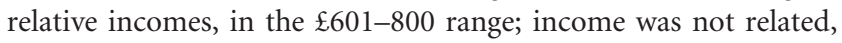
however, to any of the dependent measures.

Our hypothesis concerned differences in affection and eye gaze within the clinic group, simply requiring us to look at correlations between callous-unemotional traits and affection and eye contact scores within the clinic group. It was important first to establish base rates for the dependent variables by looking at rates in the control group and how they compared with children with conduct problems but low callous-unemotional traits. Figure 1 shows mean levels of the main dependent variables for the control group and clinic group, with callous-unemotional (CU) traits split into the bottom two-thirds and upper third percentiles to form clinic/ low-CU and clinic/high-CU groups. Caution should be used with regard to the means in the high-CU group, as these are based on small numbers. First, it should be noted that there was no
Table 1 Demographic and adjustment data for children in the control and clinical groups

\begin{tabular}{|lcc|} 
& $\begin{array}{c}\text { Clinic group } \\
n=12\end{array}$ & $\begin{array}{c}\text { Control group } \\
n=12\end{array}$ \\
\hline Age: mean (s.d.) & & \\
Child, months & $70.3(12.9)$ & $74.6(16.0)$ \\
Mother, years & $37.5(6.9)$ & $40.3(4.2)$ \\
Gender: male, $n$ (\%) & $7(58)$ & $5(41)$ \\
Two-parent family, $n$ (\%) & $6(50)$ & $7(58)$ \\
Ethnicity: Black/mixed, $n$ (\%) & $3(25)$ & $2(17)$ \\
Weekly income, UKf: median & $326-450$ & $326-450$ \\
\hline SDQ score: mean (s.d.) & & \\
Total & $15.3(5.3)$ & $5.2(3.6)^{*}$ \\
Conduct problems & $5.2(1.8)$ & $0.7(1.0)^{*}$ \\
Emotional problems & $2.8(1.9)$ & $1.1(1.8)^{*}$ \\
Hyperactivity & $4.7(1.6)$ & $2.3(1.7)^{*}$ \\
Peer problems & $2.5(2.7)$ & $1.1(1.1)^{*}$ \\
Prosocial & $5.3(1.6)$ & $8.8(1.2)^{*}$ \\
\hline APSD CU traits: mean (s.d.) & $4.8(1.4)$ & $1.3(1.3)^{*}$ \\
APSD, Antisocial Process Screening Device; CU, callous-unemotional; SDQ, Strengths \\
and Difficulties Questionnaire.
\end{tabular}

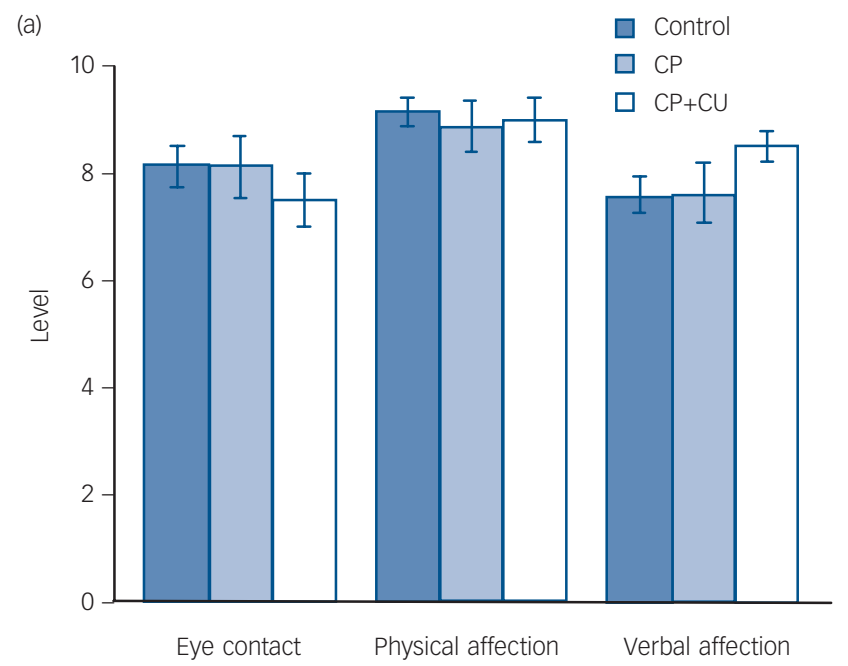

(b)

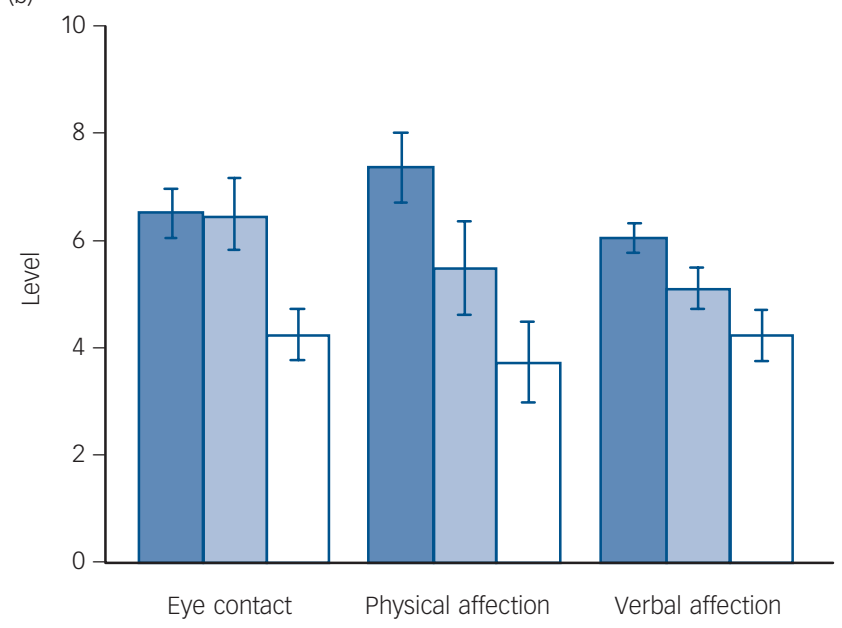

Fig. 1 Levels of eye contact and of physical and verbal affection expressed by (a) mothers and (b) children in the control group, the conduct problem group (CP) and the group with conduct problems plus callous-unemotional traits $(\mathrm{CP}+\mathrm{CU})$. Error bars show 1 standard error of the mean. 
Table 2 Correlations between callous-unemotional traits, child eye contact and parental characteristics

\begin{tabular}{|c|c|c|c|}
\hline & \multicolumn{3}{|c|}{ Correlation } \\
\hline & \multicolumn{2}{|c|}{ Mother } & \multirow{2}{*}{$\begin{array}{c}\text { Father } \\
\text { Psychopathic fearlessness }\end{array}$} \\
\hline & Positive feelings & Corporal punishment & \\
\hline \multicolumn{4}{|l|}{ Eye contact } \\
\hline Whole sample & 0.305 & -0.149 & $-0.423^{*}$ \\
\hline Clinic sample & 0.214 & 0.024 & -0.538 \\
\hline \multicolumn{4}{|c|}{ Callous-unemotional traits } \\
\hline Whole sample & $-0.538^{*}$ & $0.440^{*}$ & 0.309 \\
\hline Clinic sample & -0.151 & -0.102 & $0.629^{a}$ \\
\hline $\begin{array}{l}{ }^{*} P<0.05 . \\
{ }^{a} P<0.1 .\end{array}$ & & & \\
\hline
\end{tabular}

significant effect for levels of comfort/genuineness across the groups and these are not considered further. Analysis of variance was used to test differences between the groups on each of the affection and eye-gaze measures. There was no significant difference for any of the measures of parent behaviour (all $P>0.5)$. For child behaviour there were significant group differences for physical affection $\left(F_{(2,24)}=4.54, P<0.05\right)$, verbal affection $\left(F_{(2,24)}=5.70, P<0.01\right)$ and eye contact $\left(F_{(2,24)}=3.31\right.$, $P<0.05)$. For verbal and physical affection, highest levels were seen for children in the control group, followed by the clinic/ low-CU group, with lowest levels in the clinic/high-CU children. As predicted, there was no difference in levels of eye contact between the control and clinic/low-CU groups; children in the clinic/high-CU group showed significantly lower levels than the other two groups, however.

Next we tested correlations between callous-unemotional traits, child eye contact and the following parent self-reported characteristics: for the mother, quality of the relationship with the child (Parent Feelings Questionnaire score) and corporal punishment (Alabama Parent Questionnaire), and for the father, the fearlessness subscale of the PPI. Correlations for both the whole sample and the clinical group are shown in Table 2. Dadds et al previously found that the low levels of eye contact found for high-CU children were not simply a general index of the quality of the parent-child relationship or family environment, but were related to low eye contact in fathers. ${ }^{21}$ Mothers' positive feelings towards their child were associated with higher child eye contact and lower callous-unemotional traits in the whole sample, but not within the clinical sample. Mothers' use of corporal punishment was related to levels of callous-unemotional traits in the whole sample, but was unrelated to levels of child eye contact. The only parental characteristic related to both callousunemotional traits and child eye contact in the whole sample and in the clinic group was fearlessness in fathers, where high fearlessness was associated with high callous-unemotional traits in the child and low eye contact.

Finally, we wanted to check that the relationship between callous-unemotional traits and low eye contact was statistically robust and not confounded by other variables. The simple correlation in the clinical sample $(r=-0.504$, slope -0.728 , s.e. $=0.394)$ was based on a small sample size where assumptions of normal distribution may be violated. Non-linear regression using bootstrapping resulted in a decrease in standard error and the relationship remained significant (slope -0.728 , s.e. $=0.363$, $P<0.05)$. Next, we used partial correlations to check for any confounds to the relationship between callous-unemotional traits and eye contact. Control variables were age, gender, diagnostic severity of oppositional defiant disorder and CAST score. Although none of the children in this study had any significant symptoms of autism-spectrum disorder, we wanted to make sure that the results were not due to the presence of any (subclinical) features of this disorder, since it has long been associated with impediments in eye contact toward others (see, for example, Klin et al). ${ }^{31}$ The correlation between callous-unemotional traits and eye contact remained $(r=-0.325)$ despite the presence of the covariates.

\section{Discussion}

Children with high levels of callous-unemotional traits have difficulties recognising fear stimuli, associated with impairments in their propensity to attend to critical features of the environment that communicate fear. This is exemplified by the finding that boys with high levels of callous-unemotional traits show impaired eye contact during free interaction and emotion discussions with attachment figures. ${ }^{21}$ Our study assessed whether deficits in eye contact would also characterise an intense 'love' interaction. In terms of mothers' behaviour during the tasks, we found no difference between mothers of conduct problem children and controls in terms of their behaviour in the 'love' task. They were equally affectionate both physically and verbally, and made eye contact with their child at equal levels. Similarly, levels of callous-unemotional traits in their child did not predict their behaviour on any of these variables. There is a wealth of studies showing that parents of children with conduct problems are more coercive and less warm than control parents; however, we are aware of no other study assessing the ability to display love in a short burst. In this context, mothers of conduct problem boys appear quite capable of expressing love and affection.

The behaviour of the children was quite different, however. The children with conduct problems displayed lower levels of reciprocated verbal and physical affection, and those with high callous-unemotional traits showed lower levels than children with conduct problems but low callous-unemotional traits. Although caution is needed in generalising from a brief interaction in a clinic, these results are consistent with growing evidence that many aspects of parenting styles with conduct problem children are likely to be driven in part by child characteristics (see Pardini). ${ }^{32}$ Rearing a child who rarely reciprocates affection is likely to discourage parents from initiating affectionate behaviour, even though (as demonstrated in this study) they may be capable of doing so.

\section{Models of psychopathy}

Our main hypotheses concerned the level of reciprocated eye contact. We have previously postulated that callous-unemotional traits are associated with deficits in the extent to which children 
attend to the eye region of attachment figures and that this could drive cascading errors in the development of empathy and conscience. Other models of psychopathy similarly emphasise the importance of stimulus awareness in empathy $v$. psychopathy. Blair has argued that awareness and emotional response to distress cues in other people are necessary for developing the ability to inhibit selfish and violent behaviour. ${ }^{33}$ Newman et al argued that attention to emotional stimuli is necessary for psychopathic individuals to show normal fear responses to aversive stimuli. ${ }^{17}$ More generally, there is a burgeoning literature in the neurosciences and developmental psychopathology showing that attention to and responsiveness to emotional stimuli is a fundamental building block of the development of higher-order human functions such as empathy and theory of mind. ${ }^{34,35}$ We suggest that a simple deficit such as impairment in propensity to make eye contact with attachment figures signals the absence of a basic building block underlying social and moral development, and could explain a host of findings in the literature on psychopathy. Shaw et al provided an elegant example of such cascading errors. ${ }^{22}$ Amygdala damage early in life results in long-term impairments in higher-order social cognition, but similar damage late in life has no such effect. Impairments in amygdala responsiveness to emotional cues are a marker of psychopathy and callous-unemotional traits in children, ${ }^{36,37}$ and also in adults. ${ }^{38}$ Amygdala function is involved in the regulation of attention and responsiveness to emotional (particularly fear) stimuli. It is also centrally involved in the detection and direction of eye gaze. ${ }^{39}$ Although it is unlikely to be the only factor in the development of callous-unemotional traits and psychopathy, it is likely that low amygdala function is associated with the origins of psychopathy, that this is mediated by low attention to emotional stimuli especially the eyes of attachment figures, and that this compromises the child's responsiveness to parental discipline, affection and the development of higher-order empathic processing.

Consistent with this model, our study showed that high callous-unemotional traits are associated with deficits in eye contact with the child's primary attachment figure. We have previously demonstrated this effect in older children involved in free interactions and emotional discussions. The current study replicates this finding, but also shows that the impairment in eye contact is present in children with conduct problems as young as 4 years, occurs when the parent is deliberately making eye contact and expressing love to the child, and differs from healthy controls as well as from their peers with conduct problems but low callous-unemotional traits. Further, our study shows that this effect can be produced, with clinically significant effect sizes, in a short $90 \mathrm{~s}$ interaction that can be coded using global ratings of levels of affection and eye contact. An alternative account of our findings may be that environmental variables such as abuse history might be driving the impairments in eye contact. No standardised measure of abuse history was available in this study, but clinical review of the files showed no known history of child abuse in any of the children; three had been exposed to significant domestic violence but these children were all low in callousunemotional traits. Related environmental variables of mothers' use of corporal punishment and negative feelings towards the child were unrelated to child eye contact in the clinic sample. Consistent with Dadds et al, ${ }^{21}$ however, low child eye contact was associated with a related characteristic in fathers, in this case fearlessness. Taken together, the results suggest that low eye contact is a marker of callous- unemotional traits that is relatively independent of relationship quality and adverse parenting, but rather appears to be a trait characteristic of the male side of the family.

\section{Limitations of the study}

Some limitations of our study should be noted. First, although the sample was large enough to demonstrate the predicted effects, it is small in terms of generalising to other groups and requires replication. Second, the sample included both boys and girls; our earlier study investigated only boys, and there are many reasons to expect that the genders may differ. For example, in a large Australian sample levels of cognitive and affective empathy were quite different for boys and girls with 'psychopathic' traits. ${ }^{40}$ Thus, it is unknown how well these findings will generalise to representative samples of girls with conduct problems. Third, our coding procedure involved estimating eye contact from two cameras that were set up with sufficiently wide zoom to be able to accommodate natural movements in the room by the mothers and children. Thus some degree of inaccuracy is inevitable, but, as noted by Dadds et al, ${ }^{21}$ this is likely to underestimate any deficit in eye contact. Eye tracking studies have shown that children with high callous-unemotional traits show a similar propensity to look at faces as children with low callous-unemotional traits do; however, they tend to focus on the mouth rather than the eyes. It is likely that the low-resolution coding we used meant that instances of face/mouth gaze were inadvertently coded as eye gaze, thus overestimating levels of eye gaze for those with high levels of callous-unemotional traits.

\section{Mark R. Dadds, PhD, King's College London, Institute of Psychiatry, London, UK, and University of New South Wales, Australia; Jennifer L. Allen, PhD, Bonamy R. Oliver, PhD, Nathan Faulkner, MSc, Katherine Legge, BSc, Caroline Moul, MA Matthew Woolgar, PhD, Stephen Scott, MD, King's College London, Institute of} Psychiatry, London, UK

Correspondence: Mark R. Dadds, Department of Child and Adolescent Psychiatry, Institute of Psychiatry, De Crespigny Park, London SE5 8AF, UK. Email: m.dadds@unsw.edu.au

First received 10 Aug 2010, final revision 5 Dec 2010, accepted 20 Dec 2010

\section{Funding}

The research was funded by the Department of Children, Schools and Families through the National Academy for Parenting Research, Institute of Psychiatry, and by the National Health and Medical Research Council of Australia.

\section{References}

1 Patterson GR, DeBaryshe BD, Ramsey E. A developmental perspective on antisocial behavior. Am Psychol 1989; 44: 329-35.

2 Kazdin A. Parent Management Training: Treatment for Oppositional, Aggressive, and Antisocial Behavior in Children and Adolescents. Oxford University Press, 2005

3 Dishion TJ, Snyder J. An introduction to the special issue on advances in process and dynamic system analysis of social interaction and the development of antisocial behavior. J Abnorm Child Psychol 2004; 32: 575-8.

4 Raine A. Biosocial studies of antisocial and violent behavior in children and adults: a review. J Abnorm Child Psychol 2002; 30: 311-26.

5 Frick PJ, Viding E. Antisocial behavior from a developmental psychopathology perspective. Dev Psychopathol 2009; 21: 1111-31.

6 Frick PJ, White SF. Research review: the importance of callous-unemotional traits for developmental models of aggressive and antisocial behavior. J Child Psychol Psychiatry 2008; 49: 359-75.

7 Oxford M, Cavell TA, Hughes JN. Callous/unemotional traits moderate the relation between ineffective parenting and child externalizing problems: a partial replication and extension. J Clin Child Adolesc Psychol 2003; 32: 577-85.

8 Wootton JM, Frick PJ, Shelton KK, Silverthorn P. Ineffective parenting and childhood conduct problems: the moderating role of callous-unemotional traits. J Consult Clin Psychol 1997; 65: 301-8.

9 Hawes DJ, Dadds MR. The treatment of conduct problems in children with callous-unemotional traits. J Consult Clin Psychol 2005; 73: 737-41. 
10 Waschbusch DA, Carrey NJ, Willoughby MT, King S, Andrade BF. Effects of methylphenidate and behavior modification on the social and academic behavior of children with disruptive behavior disorders: the moderating role of callous/unemotional traits. J Clin Child Adolesc Psychol 2007; 36: 629-44.

11 Viding E, Blair RJR, Moffitt TE, Plomin R. Evidence for substantial genetic risk for psychopathy in 7-years-olds. J Child Psychol Psychiatry 2005; 46: 592-7.

12 Viding E, Jones AP, Paul JF, Moffitt TE, Plomin R. Heritability of antisocial behaviour at 9: do callous-unemotional traits matter? Dev Sci 2008; 11: $17-22$.

13 Lynam DR, Caspi A, Moffitt TE, Loeber R, Stouthamer-Loeber M. Longitudina evidence that psychopathy scores in early adolescence predict adult psychopathy. J Abnorm Psychol 2007; 116: 155-65.

14 Marsh AA, Blair RJR. Deficits in facial affect recognition among antisocia populations: a meta-analysis. Neurosci Biobehav Rev 2008; 32: 454-65.

15 Muñoz LC. Callous-unemotional traits are related to combined deficits in recognizing afraid faces and body poses. J Am Acad Child Adolesc Psychiatry 2009; 48: 554-62

16 Blair RJR, Mitchell DGV, Richell RA, Kelly S, Leonard A, Newman C, et al. Turning a deaf ear to fear: impaired recognition of vocal affect in psychopathic individuals. J Abnorm Psychol 2002; 111: 682-6.

17 Newman JP, Curtin JJ, Bertsch JD, Baskin-Sommers AR. Attention moderates the fearlessness of psychopathic offenders. Biol Psychiatry 2010; 67: 66-70.

18 Adolphs R, Gosselin F, Buchanan TW, Tranel D, Schyns P, Damasio AR. A mechanism for impaired fear recognition after amygdala damage. Nature 2005; 433: 68-72.

19 Dadds MR, Perry $Y$, Hawes DJ, Merz S, Riddell AC, Haines DJ, et al. Attention to the eyes and fear-recognition deficits in child psychopathy. Br J Psychiatry 2006; 189: 280-1.

20 Dadds MR, El Masry Y, Wimalaweera S, Guastella AJ. Reduced eye gaze explains 'fear blindness' in childhood psychopathic traits. J Am Acad Child Adolesc Psychiatry 2008; 47: 455-63.

21 Dadds MR, Jambrak J, Pasalich D, Hawes DJ, Brennan J. Impaired attention to the eyes of attachment figures and the developmental origins of psychopathy. J Child Psychol Psychiatry 2011; 52: 238-45.

22 Shaw P, Lawrence EJ, Radbourne C, Bramham J, Polkey CE, David AS The impact of early and late damage to the human amygdala on 'theory of mind' reasoning. Brain 2004; 127: 1535-48.

23 American Psychiatric Association. Diagnostic and Statistical Manual of Mental Disorders (4th edn) (DSM-IV). APA, 1994

24 Holland D, Dadds MR. The Diagnostic Interview Schedule for Children, Adolescents, and Parents. Griffith University, Brisbane, Australia, 1997.

25 Goodman R. The Strengths and Difficulties Questionnaire: a research note. J Child Psychol Psychiatry 1997; 38: 581-6.
26 Frick PJ, Hare RD. The Antisocial Process Screening Device. Multi-Health Systems, 2001.

27 Deater-Deckard K. Parenting and child behavioral adjustment in early childhood: a quantitative genetic approach to studying family processes. Child Dev 2000; 71: 468-84.

28 Scott FJ, Baron-Cohen S, Bolton P, Brayne C. The CAST (Childhood Asperger Syndrome Test): preliminary development of a UK screen for mainstream primary-school-age children. Autism 2002; 6: 9-31.

29 Shelton KK, Frick PJ, Wootton J. Assessment of parenting practices in families of elementary school-age children. J Clin Child Psychol 1996; 25 317-29.

30 Lilienfeld SO, Andrews BP. Development and preliminary validation of a selfreport measure of psychopathic personality traits in noncriminal populations. J Pers Assess 1996; 66: 488-524.

31 Klin A, Jones W, Schultz R, Volkmar F, Cohen D. Visual fixation patterns during viewing of naturalistic social situations as predictors of socia competence in individuals with autism. Arch Gen Psychiatry 2002; 59 809-16.

32 Pardini DA. Novel insights into longstanding theories of bidirectional parent-child influences: introduction to the special section. J Abnorm Child Psychol 2008; 36: 627-31

33 Blair RJR. A cognitive developmental approach to morality: investigating the psychopath. Cognition 1995; 57: 1-29.

34 Blakemore SJ. The social brain in adolescence. Nat Rev Neurosci 2008; 9: $267-77$.

35 Skuse D. Fear recognition and the neural basis of social cognition. Child Adolesc Ment Health 2003; 8: 50-60.

36 Jones AP, Laurens KR, Herba CM, Barker GJ, Viding E. Amygdala hypoactivity to fearful faces in boys with conduct problems and callous-unemotional traits. Am J Psychiatry 2009; 166: 95-102.

37 Marsh AA, Finger EC, Mitchell DGV, Reid ME, Sims C, Kosson DS, et al. Reduced amygdala response to fearful expressions in children and adolescents with callous-unemotional traits and disruptive behavior disorders. Am J Psychiatry 2008; 165: 712-20.

38 Deeley Q, Daly E, Surguladze S, Tunstall N, Mezey G, Beer D, et al. Facial emotion processing in criminal psychopathy: preliminary functional magnetic resonance imaging study. Br J Psychiatry 2006; 189: 533-9.

39 Fox E, Damjanovic L. The eyes are sufficient to produce a threat superiority effect. Emotion 2006; 6: 534-9.

40 Dadds MR, Hawes DJ, Frost AD, Vassallo S, Bunn P, Hunter $K$, et al. Learning to 'talk the talk': the relationship of psychopathic traits to deficits in empathy across childhood. J Child Psychol Psychiatry 2009; 50: 599-606. 